\title{
Urethane Dimethacrylates with Carboxylic Groups as Potential Dental Monomers. Synthesis and Properties
}

\author{
By Tinca Buruiana, ${ }^{*}$ Violeta Melinte, Lenuta Stroea, and Emil C. BurUiana
}

\begin{abstract}
New urethane dimethacrylate oligomers functionalized with carboxylic acid groups $($ CAd- $1 \div 4)$ were synthesized and evaluated as co-monomers in dental resin composites. Photopolymerization of these oligomers containing polyethylene oxide spacer was monitored by FT-IR spectroscopy comparatively with the low molecular monomer (CAd-M), as well as by fluorescence technique. The polymerization shrinkage for several mixtures including the urethane oligomers and BisGMA/ TEGDMA system was determined and, for some cured specimens, the equilibrium water uptake, water sorption and contact angle were measured to establish their behaviour into a wet environment. The compatibility between the organic and inorganic phase was investigated by SEM analysis in fractured surfaces indicating the formation of compact homogeneous materials. Aspects of the crack propagation behaviour of some composites subjected to Vickers indentation were examined by polarizing optical microscopy (POM) and atomic force microscopy (AFM), a visible crack being visible only in AFM image. Mechanical properties (compressive and diametral tensile strengths), determined for several resins composites, sustains the formation of materials with a hardness comparable to those frequently encountered in dental practice.

KEY WORDS: Dimethacrylate Oligomers / Carboxylic Groups / Dental Composites /
\end{abstract}

For decades, the commercial monomer systems intended for dental anatomy restorative applications continue to utilize bisphenol A-glycidyl dimethacrylate (BisGMA) as main component taken in combination with triethyleneglycol dimethacrylate (TEGDMA) as viscosity diluents, the latter being responsible of some deficiencies that restrict the service life and performance of the resin composites. ${ }^{1,2}$ Previous studies revealed that all acrylic formulations manifest a significant volumetric contraction that accompanies ambient polymerization of the composite matrix, followed by a polymer ageing that creates undesired effects to the users. ${ }^{3-5}$ Moreover, susceptibility to water sorption and incomplete conversion of the double bonds affects the physical and mechanical properties of the formed composites. ${ }^{6,7}$ In order to improve the characteristics of the composite materials, the approached strategies include maximization of the filler amount and/or formulating of organic phase based on BisGMA analogous, ${ }^{8,9}$ liquid crystalline or hiperbranched monomers, ${ }^{10,11}$ sol-gel polycondensates ${ }^{12}$ among other things. In tandem, a series of multi-ethylene glycol dimethacrylates of various lengths were also used as co-monomers (up to $30 \%$ ) in the organic phase owing to the notable effect on the ultimate conversion, volumetric shrinkage and mechanical properties. ${ }^{13}$ Moreover, an increased double-bond conversion in the final polymer matrix is desirable to enhance biocompatibility and reduce swelling in the later systems, compared to that of lowmolecular weight monomers (diethylene glycol dimethacrylate (DEGDMA) or TEGDMA) used currently in dental filling composites. ${ }^{14}$ Among the mentioned issues, performing of a better adhesiveness to dentin and enamel has required the development of new carboxylic acid functionalized monomers or phosphor-containing derivatives to be used as dental polymeric adhesives. ${ }^{15-18}$

A viable alternative to acrylic systems are the urethane di(meth)acrylates with an aliphatic (UDMA) or partially aromatic (TMX-UDMA) core structure, proposed initially for reducing the high viscosity of BisGMA that allow a higher filler loading and finally, attaining of a high conversion in the resin composites. ${ }^{9,11,19-22}$ An area of monomers research that has received insufficient attention is the approach of urethane di(meth)acrylates chemically modified with carboxyl groups. In this regard, it is mentioning our study on the synthesis of reactive oligomers functionalized with such adhesive groups, ${ }^{23}$ in order to assess the effects of the chemical structure of these urethane macromers and composition on the photocuring process and implicitly, on the composite properties.

Following the same motif in this article, we present the results obtained in the synthesis and characterization of acid urethane dimethacrylates bearing in a single molecule both sequences of polyethylene oxide and carboxyl groups incorporated by means of L-tartaric acid that contains a diacid function attached to the respective asymmetric carbon. A comparative study of their behaviour to photopolymerization is complemented by data obtained via fluorescence spectroscopy, using pyrene as molecular probe introduced in each dental formulation. In addition, the selected mixtures of monomers will be combined with appropriate inorganic fillers to form resin composites, whose properties will be investigated. Our earlier study evaluated the effect of pyrene fluorophore incorporated into some formulations containing modified and non-modified BisGMA, used together with other traditional monomers in the 
pursuing of specific properties during the formation of polymeric network in the resin composites. ${ }^{24,25}$

\section{EXPERIMENTAL}

\section{Materials}

Polyethylene glycol (PEG, $M_{\mathrm{w}}=400,600$ and 1000 $\mathrm{g} / \mathrm{mol}$ ), L-tartaric acid (TA), isophorone diisocyanate (IPDI), 2-hydroxyethyl methacrylate (HEMA), triethyleneglycol dimethacrylate (TEGDMA) and 2,2-bis[4-(2-hydroxy-3-methacryloyloxypropoxy)phenyl)propane] (BisGMA) were purchased from Sigma Aldrich Chemical Co. and used without further purification. The initiators used as received were camphorquinone and 4-(dimethylamino)-phenylacetic acid (DMPheAA) (from Sigma-Aldrich Chemical Co.). The filler zirconium silicate nanopowder was purchased from SigmaAldrich Chemical Co and has an average particle diameter < $25 \mathrm{~nm}$ (XRD). $\mathrm{Zr}$ and $\mathrm{Sr}$ glass (1:1): granulation under $5 \mu \mathrm{m}$ (about $97 \%$ ); density $2.9 \mathrm{~g} / \mathrm{cm}^{3}$.

\section{Oligomer Synthesis}

For the preparation of the carboxylic urethane dimethacrylate oligomers was employed the same method, reason for that the synthetic details given below are referring for one of them. Thus, $3.2 \mathrm{~g}$ ( $8 \mathrm{mmol})$ PEG of $M_{\mathrm{w}}=400 \mathrm{~g} / \mathrm{mol}$ were degassed under vacuum for $2 \mathrm{~h}$, and then, were treated with $0.3 \mathrm{~g}$ ( $2 \mathrm{mmol}$ ) TA dissolved in $3 \mathrm{~mL}$ anhydrous dimethylacetamide (DMAc) and $4.23 \mathrm{~mL}(20 \mathrm{mmol})$ IPDI. The polyaddition was carried out in the presence of dibutyltin dilaurate and in a dry nitrogen atmosphere at $55^{\circ} \mathrm{C}$ for $6 \mathrm{~h}$. Further, $2.43 \mathrm{~mL}$ (20 mmol) HEMA and $0.001 \mathrm{~g}$ hydroquinone (as inhibitor) were added and the reaction was continued at $40^{\circ} \mathrm{C}$ for other $7 \mathrm{~h}$. The course of the reaction was followed through the infrared absorption of the isocyanate stretching band at $2260 \mathrm{~cm}^{-1}$, the reaction being considered completed after the disappearance of the NCO band from spectrum. The resulting urethane dimethacrylate oligomer (CAd-1) was collected by precipitation in diethyl ether and removal of the residual solvent under vacuum. By replacement of PEG $\left(M_{\mathrm{w}}=400\right.$ $\mathrm{g} / \mathrm{mol}$ ) with PEG of $M_{\mathrm{w}}=600$ or $1000 \mathrm{~g} / \mathrm{mol}$, other two dimethacrylates (CAd-2 and respectively, CAd-3) were also obtained. Similarly, was prepared CAd-4 starting from PEG of $M_{\mathrm{w}}=400 \mathrm{~g} / \mathrm{mol}(5 \mathrm{mmol})$, IFDI $(20 \mathrm{mmol})$, TA $(5 \mathrm{mmol})$ and HEMA (20 mmol).

CAd-1. Yield: $9 \mathrm{~g}(86 \%)$. Elem. anal. (\%), calcd. for $\mathrm{C}_{50.69} \mathrm{H}_{86.57} \mathrm{~N}_{4} \mathrm{O}_{18.95}$ : C, 57.71; H, 8.21; N, 5.31; found: $\mathrm{C}$, 57.58; H, 8.17; N, 5.35.

CAd-2. Yield: $9.2 \mathrm{~g} \mathrm{(91 \% ).} \mathrm{Elem.} \mathrm{anal.} \mathrm{( \% ),} \mathrm{calcd.} \mathrm{for}$ $\mathrm{C}_{57.95} \mathrm{H}_{101.1} \mathrm{~N}_{4} \mathrm{O}_{22.58}$ : C, 57.28; $\mathrm{H}, 8.33 ; \mathrm{N}, 4.61$; found: $\mathrm{C}$, 57.41; H, 8.37; N , 4.58. ${ }^{1} \mathrm{H}$ NMR (DMSO, $\delta$ ppm): 8.23, 7.93, 7.16-7.02 (4 H, N $\underline{H}) ; 6.06\left(\mathrm{~d}, 2 \mathrm{H}, \mathrm{CH}_{2}=\mathrm{C}\right.$ in trans position relative to $\mathrm{CH}_{3}$ unit from HEMA); $5.66\left(\mathrm{~s}, 2 \mathrm{H}, \mathrm{CH}_{2}=\mathrm{C}\right.$ in cis position relative to $\mathrm{CH}_{3}$ unit from HEMA); 4.25-4.03 (m, $8 \mathrm{H}$, $\mathrm{CH}_{2}-\mathrm{NH}$ and $\left.\mathrm{CH}_{2}-\mathrm{O}-\mathrm{CO}\right) ; 3.67-3.51\left(\mathrm{~m}, 42.3 \mathrm{H}, \mathrm{CH}_{2}-\mathrm{CH}_{2}\right.$ from PEO); 1.87 (s, $6 \mathrm{H}, \mathrm{CH}_{3}$ from HEMA); 1.44-0.76 (m, 15 $\mathrm{H}$, isophorone unit).
CAd-3. Yield: $8.3 \mathrm{~g}(86.6 \%)$. Elem. anal. (\%), calc. for $\mathrm{C}_{72.49} \mathrm{H}_{130.2} \mathrm{~N}_{4} \mathrm{O}_{29.85}$ : C, 56.7; H, 8.48; N, 3.65; found: $\mathrm{C}$, 56.68; $\mathrm{H}, 8.45 ; \mathrm{N}, 3.61 .{ }^{1} \mathrm{H} \mathrm{NMR}\left(\mathrm{CDCl}_{3}, \delta \mathrm{ppm}\right): 7.93(4 \mathrm{H}$, $\mathrm{NH}) ; 6.07\left(\mathrm{~d}, 2 \mathrm{H}, \mathrm{CH}_{2}=\mathrm{C}\right.$ in trans position relative to $\mathrm{CH}_{3}$ unit from HEMA); 5.52 (s, $2 \mathrm{H}, \mathrm{CH}_{2}=\mathrm{C}$ in cis position relative to $\mathrm{CH}_{3}$ unit from HEMA); 5.01-4.73 (m, 2H, -O-Cㅌ-COOH); 4.32-4.11 (m, 8 H, $\underline{\mathrm{CH}}_{2}-\mathrm{NH}$ and $\left.\mathrm{CH}_{2}-\mathrm{O}-\mathrm{CO}\right) ; 3.78-3.65(\mathrm{~m}$, $71.4 \mathrm{H}, \mathrm{CH}_{2}-\underline{\mathrm{CH}}_{2}$ from PEO); 1.88 (s, $6 \mathrm{H}, \mathrm{CH}_{3}$ from HEMA); 1.4-0.8 (m, $15 \mathrm{H}$, isophorone unit).

CAd-4. Yield: $12.05 \mathrm{~g}(82 \%)$. Elem. anal. (\%), calc. for $\mathrm{C}_{46.68} \mathrm{H}_{77.36} \mathrm{~N}_{4} \mathrm{O}_{17.84}$ : C, 57.21; H, 7.9; N, 5.72; found: C, 57.18; H, 7.95; N, 5.69. ${ }^{1} \mathrm{H}$ NMR (DMSO, $\delta$ ppm): 7.93, 7.19$7.04(4 \mathrm{H}, \mathrm{NH}) ; 6.06\left(\mathrm{~d}, 2 \mathrm{H}, \mathrm{CH}_{2}=\mathrm{C}\right.$ in trans position relative to $\mathrm{CH}_{3}$ unit from HEMA); $5.66\left(\mathrm{~s}, 2 \mathrm{H}, \mathrm{CH}_{2}=\mathrm{C}\right.$ in cis position relative to $\mathrm{CH}_{3}$ unit from HEMA); 4.24-4.03 (m, 8H, $\mathrm{CH}_{2}-\mathrm{NH}$ and $\left.\mathrm{CH}_{2}-\mathrm{O}-\mathrm{CO}\right)$; 3.67-3.5 (m, $17.36 \mathrm{H}, \mathrm{CH}_{2}-\mathrm{CH}_{2}$ from $\mathrm{PEO}$ ); 1.87 (s, 6H, $\mathrm{CH}_{3}$ from HEMA); 1.42-0.76 (m, 15H, isophorone unit).

The same procedure was adopted for preparing urethane dimethacrylate oligomer without carboxylic groups (UDMA-1) starting from $\mathrm{PEG}_{1000}$ :IPDI:HEMA taken in the molar ratio $1: 2: 2$, as previously reported. ${ }^{25}$

\section{Monomer Synthesis}

The dicarboxylic urethane dimethacrylate monomer was synthesized by reacting $1 \mathrm{~g}(6.6 \mathrm{mmol})$ TA with $2.82 \mathrm{~mL}$ (13 mmol) IPDI in $5 \mathrm{~mL}$ of anhydrous DMAc in the presence of dibutyltin dilaurate. The mixture was stirred at $55^{\circ} \mathrm{C}$ for $6 \mathrm{~h}$ and then were added $1.6 \mathrm{~mL}(13 \mathrm{mmol}) \mathrm{HEMA}$ at $40^{\circ} \mathrm{C}$, the stirring being continued for $7 \mathrm{~h}$. The above reaction was also verified through the infrared absorption of the isocyanate stretching band at $2260 \mathrm{~cm}^{-1}$, following the disappearance of this band from the spectrum. The acid urethane dimethacrylate monomer (CAd-M) was purified by precipitation in diethyl ether, the solvent being removed under reduced pressure.

CAd-M. Yield: $4.9 \mathrm{~g}(86 \%)$. Elem. anal. (\%), calc. for $\mathrm{C}_{40} \mathrm{H}_{62} \mathrm{~N}_{4} \mathrm{O}_{16}$ : C, 56.20; H, 7.26; N, 6.55; found: C, 56.17; $\mathrm{H}, 7.29$; N, 6.58. ${ }^{1} \mathrm{H}$ NMR (DMSO, $\delta$ ppm): 7.95, 7.22-7.07 $(4 \mathrm{H}, \mathrm{NH}) ; 6.07$ (d, $2 \mathrm{H}, \mathrm{CH}_{2}=\mathrm{C}$ in trans position relative to $\mathrm{CH}_{3}$ unit from HEMA); $5.69\left(\mathrm{~s}, 2 \mathrm{H}, \mathrm{CH}_{2}=\mathrm{C}\right.$ in cis position relative to $\mathrm{CH}_{3}$ unit from HEMA); 4.26-4.1 (m, $8 \mathrm{H}, \mathrm{C}_{2}-\mathrm{NH}$ and $\mathrm{CH}_{2}-\mathrm{O}-\mathrm{CO}$ ); 1.88 (s, $6 \mathrm{H}, \mathrm{CH}_{3}$ from HEMA); $1.48-0.88$ (m, $15 \mathrm{H}$, isophorone unit). IR $\left(\mathrm{KBr}, \mathrm{cm}^{-1}\right): 3350(\mathrm{NH}) ; 2870$ $2950\left(\mathrm{CH}_{2}\right) ; 1720(\mathrm{C}=\mathrm{O}) ; 1640$ and $815\left(\mathrm{CH}_{2}=\mathrm{CH}\right) ; 1530$ (amide II); 1200 and 1115 (C-O-C).

\section{Characterization}

The monomer and oligomers structures were verified by ${ }^{1} \mathrm{H}$ NMR and FT-IR spectroscopy using a Bruker $400 \mathrm{MHz}$ spectrometer and a Bruker Vertex 70 spectrophotometer, respectively. UV-visible irradiation were performed with a dental device (LA 500, Blue Light, $\lambda=400-500 \mathrm{~nm}$, intensity of light $60 \mathrm{~mW} / \mathrm{cm}^{2}$ ) and the conversion of double bonds was determined by FT-IR absorption spectroscopy. A mixture of acid urethane acrylic oligomer and photoinitiator [4-(dimethylamino)-phenylacetic acid (DMPheAA, 1\%)/camphorquinone 
$(\mathrm{CQ}, 0.5 \%)]$ was homogenized and manually coated on the $\mathrm{KBr}$ plate. The FT-IR absorption spectra were measured as a function of irradiation time and the degree of conversion was determined from the differences appeared in the $\mathrm{C}=\mathrm{C}$ stretching vibration at $1637 \mathrm{~cm}^{-1}$ or the $\mathrm{C}=\mathrm{C}$ twisting vibration at $816 \mathrm{~cm}^{-1} .^{26}$ The fluorescence spectra were obtained at room temperature (without corrections) with an SLM 8000 spectrofluorimeter (Japan) containing a double monochromator with a diffraction network of the GDM-1000 type, a compensatory printer of the K-201 type, and a selective amplifier. Viscosity measurements of the oligomers $(10 \mathrm{~g})$ were determined with a Brookfield cone and plate viscometer at room temperature. The test was run at spindle speeds of $6 \mathrm{rpm}$ and the viscosity readings obtained were recorded and expressed as Pascal second ( $\mathrm{Pas}$ ). The microstructure of the composites in fracture was examined under scanning electron microscopy, SEM (Vega Tescan 5130-LS instrument), the specimens being sputter-coated with gold. Water contact angle measurements were made on relatively homogeneous surface using goniometer KSV Cam 200. The average contact angle was calculated starting from at least ten separate measurements. The polymerization shrinkage of cured and uncured specimens tested in the present study was determined by the density bottle method, at room temperature. Photocurable pastes for shrinkage measurement were formulated using a weight ratio of urethane monomer:BisGMA:TEGDMA:CQ:DMPheAA of $15: 49.25: 34.25: 0.5: 1$. The specimens in the form of small cylinders (approximately $0.2 \mathrm{~g}$ in weight) were placed in a density bottle of $20 \mathrm{~cm}^{3}$ volume containing distilled water $\left(q_{\mathrm{H} 2 \mathrm{O}}\right.$ at $\left.25^{\circ} \mathrm{C}=0.99707 \mathrm{~g} / \mathrm{cm}^{3}\right)$. A Partner balance (accuracy $= \pm 0.000001 \mathrm{~g}$ ) was used. Three successive measurements for all tested composites were performed. The polymerization shrinkage was determined separately for each specimen using the eq 1 :

$$
\text { Polymerization shrinkage }=\frac{d_{\text {cured }}-d_{\text {uncured }}}{d_{\text {cured }}} \times 100
$$

where, $d$ is the density of the formulation. For water sorption determinations, four disk specimens of reduced dimensions ( $15 \pm 0.1 \mathrm{~mm}$ diameter, $1 \pm 0.1 \mathrm{~mm}$ thickness) were prepared for each group of mixtures, using a Teflon split ring mould between two glass plates covered with polyethylene film. The composites were pre-conditioned over a desiccant containing calcium sulfate at $37^{\circ} \mathrm{C}$ until their weight remain constant (initial weight $m_{1}$ ). Further, specimens were placed in distilled water at $37^{\circ} \mathrm{C}$ for different time intervals and then removed from the water, lightly blotted with a paper to eliminate the surface-adherent water, and weighed. After three weeks $\left(m_{2}\right)$, specimens were placed into a desiccator with calcium sulfate and dried at $37^{\circ} \mathrm{C}$ until their weight was constant again $\left(m_{3}\right)$. The water solubility for each sample was determined using the eq 2:

$$
\text { Water solubility }(\text { wt. } \%)=\frac{m_{1}-m_{3}}{m_{1}} \times 100
$$

whereas, the water sorption was calculated employing eq 3 :

$$
\text { Water sorption }(\text { wt. } \%)=\frac{m_{2}-m_{3}}{m_{1}} \times 100
$$

Compressive (CS) and diametral tensile strengths (DTS) were measured using a Shimadzu AGS-J testing machine, with a $5 \mathrm{kN}$ load cell. Specimens for the compressive strength and diametral tensile strength tests were prepared by mixing the components using a metal spatula and filling five metal cylinder moulds, all of $8 \mathrm{~mm}$ in height and $4 \mathrm{~mm}$ in diameter, which were prewaxed to prevent material adhesion. A crosshead speed of $1 \mathrm{~mm} / \mathrm{min}$ was applied in these tests. The compressive strength was calculated from the equation $\mathrm{CS}=P / \pi r^{2}$, where $P$ is the load at fracture and $r$ the radius of the sample cylinder. Diametral tensile strength was calculated from the relationship DTS $=2 P / \pi d t$, where $d$ is the diameter and $t$ the thickness, respectively, of the cylinder. The Vickers indentation method was utilized to provide controlled damage to the resin composites. The samples were prepared as disc shapes with diameter of $10 \mathrm{~mm}$ and thickness of $2 \mathrm{~mm}$. A Shimadzu HMV-2 micro hardness tester were employed to indent the specimens with a Vickers pyramid, using a force of $10 \mathrm{~N}$ and a loading time of $12 \mathrm{~s}$. Tests were repeated five times for each material and the resulting indentations were evaluated with an optical microscope (Leica DM $2500 \mathrm{M}$ ) and an AFM atomic force microscope (SOLVER PRO-M).

\section{RESULTS AND DISCUSSION}

\section{Preparation}

The synthesis route followed for the preparation of polymerizable urethane polyethylene oxide dimethacrylates containing carboxylic acid groups is depicted in Scheme 1, where is given an idealized structure of the macromers. The chemistry of urethane oligomers involved a classical polyaddition reaction of the polyethylene glycol (PEG) and tartaric acid (TA) with isophorone diisocyanate to form a prepolymer with end isocyanate groups, which finally, is functionalized to dimethacrylate by its reaction with 2-hydroxyethyl methacrylate. Although the reaction of isocyanate with hydroxyl groups from both monomers is performed by minimizing the occurrence of side reactions, it does not provide strict control over the composition of the resulting product, but the simplicity of the procedure, widely exploited to prepare polyurethane anionomers ${ }^{27}$ may be advantageous in applications for which a narrow polydispersity is not necessary. However, depending on the PEG average molecular weight $\left(M_{\mathrm{w}}: 400,600,1000 \mathrm{~g} / \mathrm{mol}\right)$ and the molar ratio between partners, four carboxylic urethane macromers (CAd-1 $\div 4)$ that differ by the length of the spacer connecting the methacrylate units on the both side were prepared to be tested as co-monomers in resin-based dental materials, and to evaluate the crosslinked network parameters. For comparison, the corresponding low molecular carboxyl monomer (CAd-M) was obtained, too (Scheme 2). The abbreviations and compositions of the synthesized urethane dimethacrylates are shown in Table I, but two observations 


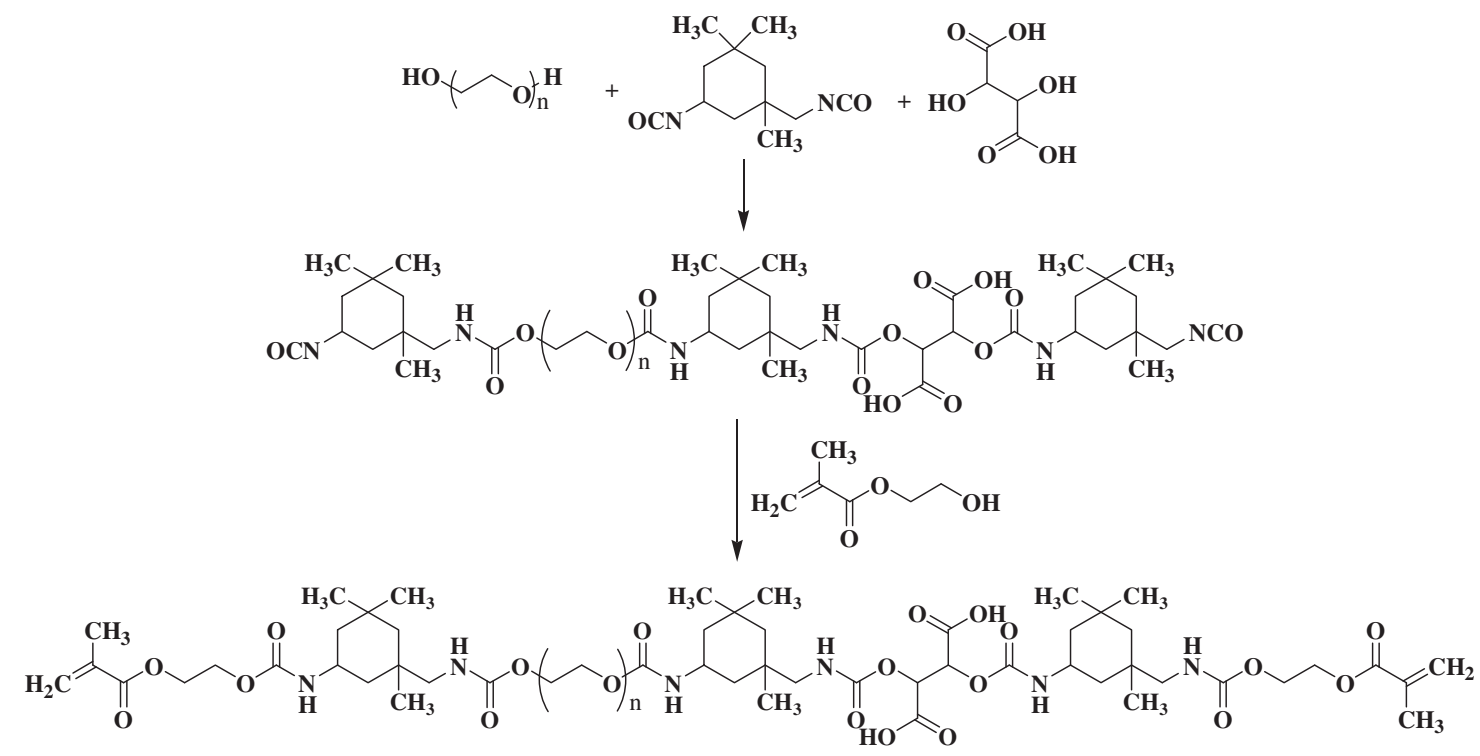

Scheme 1. Synthesis of urethane dimethacrylate oligomers with two carboxylic groups (CAd-1 $\div 4)$.
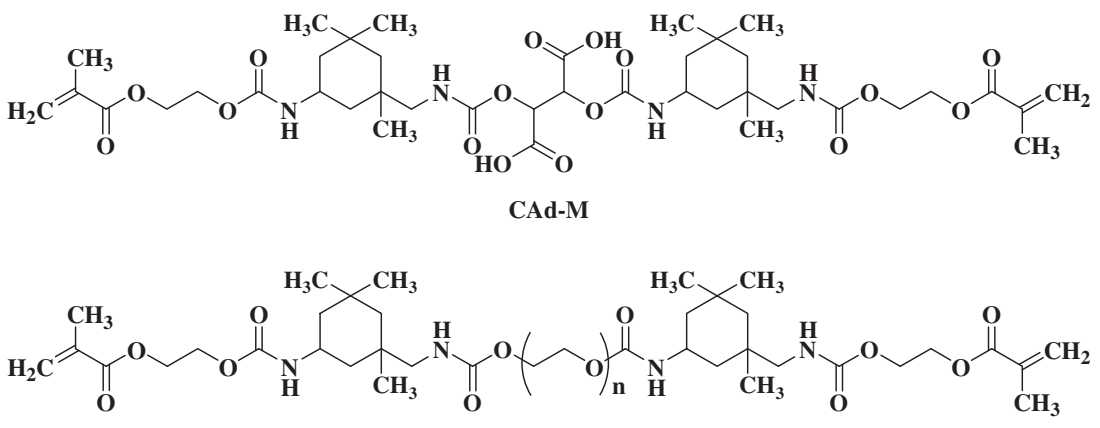

UDMA-1

Scheme 2. Structure of the acid acrylic monomer (CAd-M) and noncarboxylic oligomer UDMA-1

Table I. Relevant characteristics of the synthesized urethane dimethacrylates

\begin{tabular}{|c|c|c|c|c|}
\hline Sample & $\begin{array}{l}\mathrm{PEG}, M_{\mathrm{w}} \\
(\mathrm{g} / \mathrm{mol})\end{array}$ & $\begin{array}{c}\text { Molar ratio } \\
\mathrm{OH} / \mathrm{NCO}\end{array}$ & $\begin{array}{c}\text { Carboxyl } \\
\text { content }(\%)\end{array}$ & $\begin{array}{c}\text { Degree of } \\
\text { conversion* }(\%)\end{array}$ \\
\hline CAd-1 & 400 & $\begin{array}{c}\text { PEG:IPDI:TA:HEMA } \\
\text { 0.8:2:0.2:2 }\end{array}$ & 8.5 & 58.8 \\
\hline CAd-2 & 600 & $\begin{array}{c}\text { PEG:IPDI:TA:HEMA } \\
\text { 0.8:2:0.2:2 }\end{array}$ & 7.4 & 51.8 \\
\hline CAd-3 & 1000 & $\begin{array}{c}\text { PEG:IPDI:TA:HEMA } \\
0.8: 2: 0.2: 2\end{array}$ & 5.8 & 46.5 \\
\hline CAd-4 & 400 & $\begin{array}{c}\text { PEG:IPDI:TA:HEMA } \\
0.5: 2: 0.5: 2\end{array}$ & 9.2 & 59.7 \\
\hline CAd-M & - & $\begin{array}{c}\text { IPDI:TA:HEMA } \\
2: 1: 2\end{array}$ & 10.5 & 65.4 \\
\hline
\end{tabular}

*35 s irradiation.

have to be mentioned. First, all acid urethane dimethacrylates are uncoloured and clear viscous liquids, soluble in organic solvents as acetone, chloroform, methylene chloride, tetrahydrofuran (THF) and dimethylsulfoxide (DMSO), as well as in the photocurable acrylic monomers encountered in commer- cial resin composites (TEGDMA, BisGMA). Secondly, the viscosity values of these monomers are situated between 2.3 $2.5 \mathrm{~Pa} \mathrm{~s}$

The proposed structures of all synthesized monomers were confirmed by elemental analysis, ${ }^{1} \mathrm{H}$ NMR and FT-IR spectroscopy. ${ }^{1} \mathrm{H}$ NMR study on CAd-1 (Figure 1) reveals the presence of a peak centred at $8 \mathrm{ppm}$ corresponding to the urethane protons, while the unsaturated aliphatic protons in trans- and respectively, cis-configuration relative to the $\mathrm{CH}_{3}$ unit from HEMA can be observed at $6.15 \mathrm{ppm}$ and $5.6 \mathrm{ppm}$. Other chemical shifts were found in the spectral region for methylene protons from the ester-urethane groups and the ester unit of HEMA (4.32-4.28 ppm); methyne protons from the ester-urethane $(4.2 \mathrm{ppm})$ and methylene protons from PEO (3.65 ppm); $\mathrm{CH}_{3}$ protons from HEMA (1.96 ppm) and protons on the isophorone cycle $(1.22-0.88 \mathrm{ppm})$. Taking into account the integral ratio of methylene protons from PEO (3.65 ppm) vs. unsaturated protons $(5.6-6.15 \mathrm{ppm})$ and protons from isophorone $(1.22-0.88 \mathrm{ppm})$ it can appreciate correctly the proposed structure for the aforementioned urethane dimethacrylate macromers. 


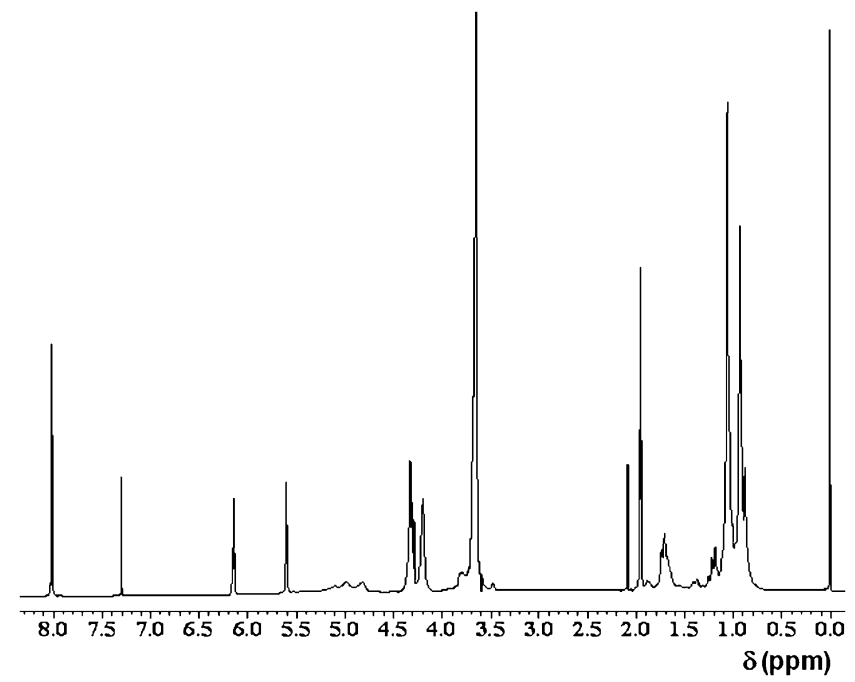

Figure 1. ${ }^{1} \mathrm{H}$ NMR spectrum of poly(ethylene oxide) urethane dimethacrylate with carboxylic groups (CAd-1) in DMSO- $d_{6}$.

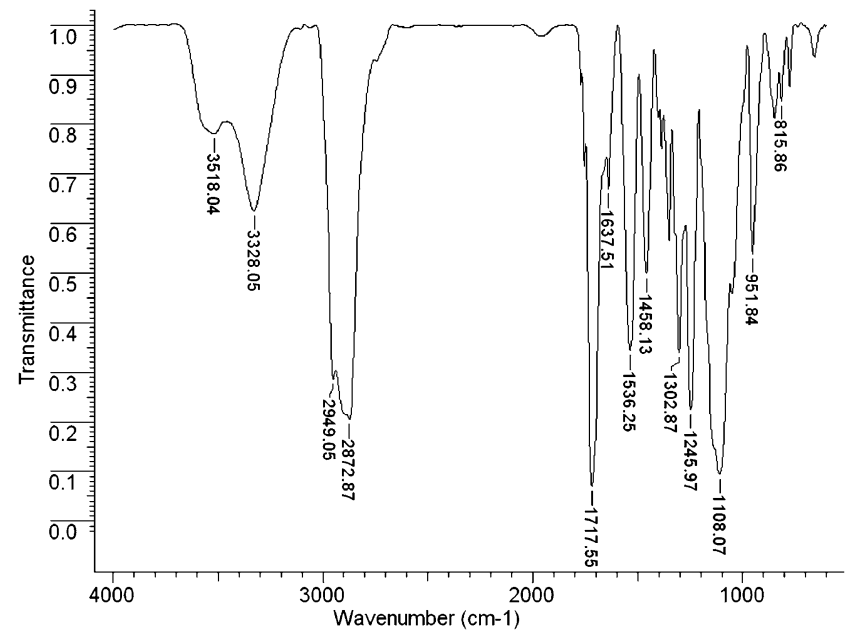

Figure 2. FT-IR spectrum of poly(ethylene oxide) urethane dimethacrylate with carboxylic groups (CAd-2).

The FT-IR spectra of acidic urethane dimethacrylate oligomers (e.g., FT-IR spectrum of CAd-2 is shown in Figure 2) exhibit specific absorption bands attributed to urethane $\mathrm{NH}\left(3500-3320 \mathrm{~cm}^{-1}\right)$, the vibrations of the $\mathrm{CH}_{2}$ groups (2870-2950 $\mathrm{cm}^{-1}$ ) and carbonyl unit (CO) from the urethane, as well as to the ester and acid moieties $\left(1717 \mathrm{~cm}^{-1}\right)$. The absorption bands for carbon-carbon double bond on the methacrylate function can be detected at 1637 and $816 \mathrm{~cm}^{-1}$, the amide II vibration at $1536 \mathrm{~cm}^{-1}$, and the C-O-C unit in the region $1100-1245 \mathrm{~cm}^{-1}$.

\section{Photopolymerization}

Since the chemical structure and the relative concentration of each multifunctional macromer can have a marked effect on the mobility and kinetics of polymerization, the photobehavior of the urethane dimethacrylates was investigated upon its exposure to UV-visible light ( $\lambda$ : 400-500 nm), using 4(dimethylamino)-phenylacetic acid (DMPheAA, $1 \mathrm{wt} \%$ ) and

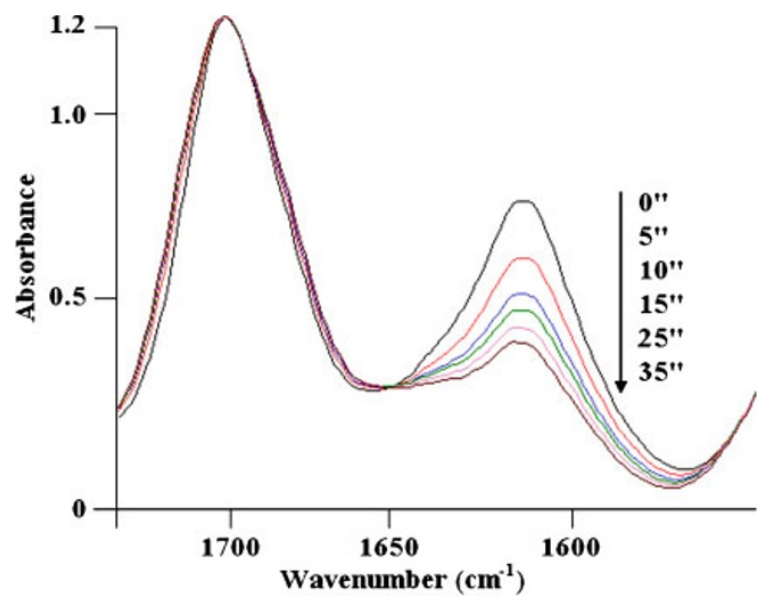

Figure 3. Changes of the double bond absorption band in the FT-IR spectrum for the carboxylic urethane dimethacrylate (CAd-4) and DMPheAA/CQ upon irradiation.

camphorquinone (CQ, $0.5 \mathrm{wt} \%$ ) as photoinitiator system. Under given conditions of photopolymerization, the macromers are subsequently homo(co)polymerized up to the formation of a hard polymer. This process was visualized through FT-IR spectroscopy, monitoring the decrease of the stretching vibration of the acrylic function after UV-vis irradiation. As shown in Figure 3, for the macromer CAd-4 the absorption band of aliphatic double bond at $1637 \mathrm{~cm}^{-1}$ monotonically decreased with increasing irradiation time, whereas the carbonyl double bond at $1716 \mathrm{~cm}^{-1}$ remains unchanged. Therefore, in the absence of a diluent co-monomer and filler, the degree of vinyl conversion (DC) attained after $35 \mathrm{~s}$ of irradiation of the CAd-4 is about $60 \%$ in the polymeric resin. In line with this finding, DC values of 55-80\% were observed for other lightactivated dental carboxyl dimethacrylate resins. ${ }^{28}$ Following the same homopolymerization process for each of the monomers investigated (Table I) it was found that there was no substantial change in the double-bond conversion of the acid urethane dimethacrylates (CAd-1, CAd-2, CAd-3 and CAd-M). This remark is not in agreement with expectations, because the double-bond conversion should increase monotonically with increasing distance between the polymerizable groups and the flexibility of the spacer from monomer (for instance, the DC ranged from 0.68 in the case of non-acid polyethylene glycol dimethacrylate (PEG200DMA) to 1.00 in PEG600DMA). ${ }^{13} \mathrm{At}$ this point we could only suggest a tentative explanation for the above result, namely, the existence of stronger hydrogen bonding interactions in our urethane dimethacrylates that induce the assembly of photocured composites with greater strength than those where there are no hydrogen bonds.

\section{Fluorescent Probe for Monitoring Photopolymerization}

Furthermore, the free-radical photopolymerization of the monomers and composites was monitored against reaction time and correlated with fluorescence data. To examine the specific properties of the molecular microenvironment during the photopolymerization of urethane dimethacrylates, a small 

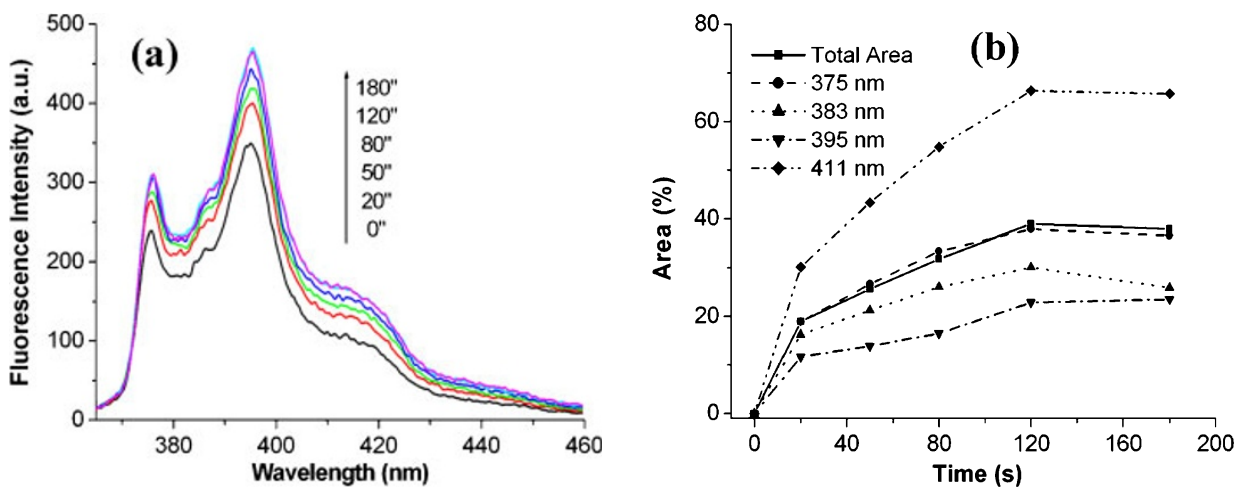

Figure 4. Monitoring the photopolymerization of CAd-3 initiated by DMPheAA/CQ, and Zr/Sr glass (70 wt. \%) via fluorescence method using pyrene methanol probe $\left(\lambda_{\mathrm{exc}}=353 \mathrm{~nm}\right)(\mathrm{a})$ and the evolution of the monomer fluorescence intensity area $(\mathrm{b})$.

amount of pyrene methanol was incorporated as fluorescent probe in any formulation that could mimic some polyacidmodified composite resins, often defined as compomers. ${ }^{29}$ This choice is motivated by the fact that an important application of fluorescent probes in polymer chemistry consists in the in situ monitoring of the polymerization process. ${ }^{30}$ Structurally, if the response of the "fluoroprobe" is sensitive to the polarity of its environment and follow well-established patterns, it specifically fit for such purpose. As anticipated, the transient fluorescent and motional characteristics of the pyrene probe could afford information around the formation of highly crosslinked polymeric network, when the emission maxima for probe in different dimethacrylates are measured as a function of irradiation time. In Figure 4(a) are given the fluorescence spectra recorded for a formulation based on CAd-3, pyrene methanol (0.5 wt. \%), DMPheAA (1 wt. \%)/CQ (0.5 wt. \%) and about $70 \mathrm{wt} \% \mathrm{Zr} / \mathrm{Sr}$ glass as filler. Upon irradiation of this combination with UV-visible light and exciting at $353 \mathrm{~nm}$, the above carboxylic urethane oligomer starts to polymerize so that, after $180 \mathrm{~s}$, a clear and glassy solid can be prepared. The vibronic fluorescence spectrum is typical to the pyrene fluorescence displaying four peaks positioned at $375 \mathrm{~nm}\left(\mathrm{I}_{1}\right), 383 \mathrm{~nm}\left(\mathrm{I}_{2}\right), 395 \mathrm{~nm}\left(\mathrm{I}_{3}\right)$ and $411 \mathrm{~nm}\left(\mathrm{I}_{4}\right)$, all assigned to the monomer fluorescence. Therefore, an excimer emission resulted from the encounter between an excited pyrene and a pyrene molecule in its ground state or by direct excitation of aggregates (dimers) cannot be detected in such pyrene-doped composite. Moreover, the excimer formation being a viscosity dependent process and implicitly, of mobility of the excited probe as well as its concentration, it is clear that the appearance of excimers is not favoured. It is evident that the photoresponse of pyrene molecule indicated that the spontaneous emission increases in intensity with irradiation time (Figure 4(b)). This seems to be consistent with a picture where the fluorescence quenching was rather restricted in the polymerization process, owing to the distribution of the involved species that limited the pyrene-pyrene hydrophobic interaction. Thus, the non-radiative energy process is diminished and consequently, the photon emission is preferred as the microviscosity continues to increase in the above composite incorporating a high amount of inorganic filler. On the other

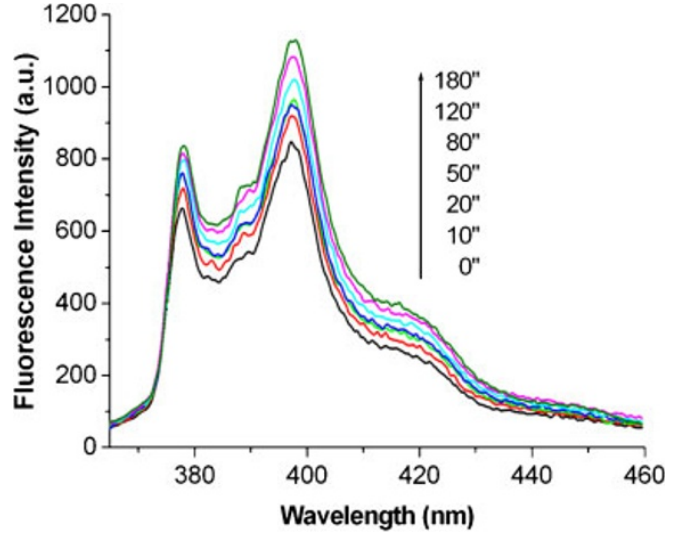

Figure 5. Monitoring the photopolymerization of a the CAd-M dimethacrylate in the presence of DMPheAA/CQ/pyrene system and $\mathrm{Zr} / \mathrm{Sr}$ glass filler, via fluorescence method.

hand, the intensity ratio of the first and third vibrational bands $\left(\mathrm{I}_{1} / \mathrm{I}_{3}\right.$ ratio) provides data about its local environment of the pyrene in the formed composite resins. In this case, the pyrene emission $I_{1} / I_{3}$ ratio varied slightly from 0.35 to 0.32 with increasing irradiation times (180 s), suggesting a hydrophobic environment around the molecular probe in the polymeric matrix.

The similarity in results continues with formulation prepared with acid dimethacrylate monomer (CAd-M) used together with DMPheAA/CQ, $\mathrm{Zr} / \mathrm{Sr}$ glass and pyrene probe. As it can be seen in Figure 5, the examination of data rising from the fluorescence is fitting to those previously discussed. Again, the microviscosity changes that occur during polymerization confirms that the rapid increase in fluorescence intensity can be viewed as measure of hardening sample during photopolymerization of the urethane monomers to produce highly crosslinked polymer networks with desirable properties.

\section{Polymerization Shrinkage}

The aim of this study being focused on the development of novel acid urethane dimethacrylates for the dental applications, it was necessary to prepare a number of resin composites formulated with a mixture of urethane monomer (CAd): 
Table II. Contact angles, water sorption, water solubility, Vickers hardness and polymerization shrinkage for some resin composites (each contain $70 \%$ wt. zirconium silicate nanopowder)

\begin{tabular}{ccccccc}
\hline Sample & Formulation* & $\begin{array}{c}\text { Angle } \\
\text { value } \\
\left({ }^{\circ}\right)\end{array}$ & $\begin{array}{c}\text { Water } \\
\text { sorption } \\
\text { (wt. \%) }\end{array}$ & $\begin{array}{c}\text { Water } \\
\text { solubility } \\
\text { (wt. \%) }\end{array}$ & $\mathrm{H}_{\mathrm{v}}$ & $\begin{array}{c}\text { Polymerization } \\
\text { shrinkage** } \\
(\%)\end{array}$ \\
\hline S1 & $15 \%$ CAd-1 & 36.22 & 2.00 & 0.34 & 30.5 & 5.4 \\
S2 & $15 \%$ CAd-2 & 38.66 & 2.28 & 0.18 & 36.3 & 6.1 \\
S3 & $15 \%$ CAd-3 & 36.55 & 2.33 & 0.12 & 37.7 & 6.7 \\
S4 & $15 \%$ CAd-4 & 38.59 & 1.96 & 0.22 & 37.1 & 5.0 \\
S5 & $15 \%$ CAd-M & 45.41 & 2.03 & 0.68 & 34.5 & 4.8 \\
S6 & $15 \%$ UDMA-1 & 41.14 & 2.09 & 0.23 & 34.9 & 7.3 \\
\hline
\end{tabular}

*Each formulation contain 49.25 wt. \% bisGMA, 34.25 wt. \% TEGDMA and is initiated with 0.5 wt. $\% \mathrm{CQ}$ and 1 wt. $\%$ DMPheAA. ${ }^{* *}$ Without filler.

\section{BisGMA:TEGDMA:CQ:DMPheAA}

(15:49.25:34.25:0.5:1 wt. \%) and 70 wt. \% zirconium silicate nanopowder (S1-S5, Table II). In order to evidence the influence of carboxyl groups on the cured materials properties, a supplementary composite based on urethane dimethacrylate without carboxyl groups (UDMA-1, Scheme 2), ${ }^{25}$ was prepared too. Investigations of the polymerization shrinkage for the formulations S1-S6 without using any filler revealed that the obtained results are comparable with the literature data, taking into account the small amount of urethane dimethacrylate oligomer included in each specimen, of only $15 \mathrm{wt} . \%$. Therefore, the incorporation of polyether sequences with variable length $\left(\mathrm{PEG}_{400}-\mathrm{PEG}_{1000}\right)$ in the organic matrix led to an increasing of the polymerization shrinkage ( $\mathrm{PS}=5.0 \div 6.7 \%$ ) as compared to the formulation comprising the monomer CAd-M $(\mathrm{PS}=4.8 \%)$. It means that the degree of shrinkage of a composite is directly related to the molecular weight of the monomer, the amount of monomer from the composite and its conversion. ${ }^{31}$ Thus, in our case, the lower conversion degree obtained for the CAd-3 oligomer gives also the highest polymerization shrinkage (6.7\%), when this was incorporated in the S3 formulation. For other photopolymerizable systems, the polymerization shrinkage values are between 5.26 and $6.06 \%$, comparable with those determined for dental formulations comprising related components. ${ }^{32}$ The polymerization shrinkage measured for S6 formulation that contains UDMA-1 oligomer (without carboxylic groups) had the highest value $(7.3 \%)$, denoting that the presence of carboxylic groups with adhesive properties into photopolymerizable mixtures confer them a slow improvement of the volumetric shrinkage, probably due to a tightly packaging of the polymer network after polymerization. This tends to confirm that the using of more adhesive bonding agents could counteract polymerization shrinkage and the resulting stresses. ${ }^{33}$

\section{Water Uptake and Solubility Measurements}

Most important characteristics of these materials are related to the water sorption and leaching of small molecules, two processes which take place simultaneously, when composite resins are in contact with water and oral fluids. For this reason, water sorption is a key parameter which guarantees viability and quality of such materials. Moreover, water sorption is a diffusion-controlled process that produces in the organic resin matrix and mainly depends on hydrophilicity ${ }^{34}$ and crosslinking density of the cured resins. ${ }^{35}$ Obviously, hydrophilic constituents increased water sorption values and thus, it is expected that the composites enclosing dicarboxylic urethane dimethacrylates of oligomer type to behave adequately. The analysis of the data included in Table II and obtained on composites prepared from the same materials as for the polymerization shrinkage, which additionally contain $70 \mathrm{wt} \%$ filler (zirconium silicate nanopowder), allow us to affirm that the dental composite resins comprising the urethane dimethacrylate oligomer CAd-3, with PEG of $1000 \mathrm{~g} / \mathrm{mol}$ in its structure shows the higher percent of water sorption $(2.33 \%)$ comparatively to the other samples, but the values are similar or even smaller than the literature ones. ${ }^{36}$ Also, it may be noticed, that composite S6 incorporating PEG of $1000 \mathrm{~g} / \mathrm{mol}$, but without carboxyl groups, had water sorption value similar with those obtained by using the monomer CAd-M or carboxylic urethane dimethacrylate based on PEG $400 \mathrm{~g} / \mathrm{mol}$ (S1 and S4). Regarding the water solubility experiments, the composite containing the acid urethane monomer (S5) presents the higher percent of water solubility, probably due to an incomplete connecting of the low molecular weight dimethacrylate in the resulting photocrosslinked matrix. However, the results obtained are good, in agreement to those reported for other dental materials. ${ }^{37}$

\section{Surface Property-Contact Angle}

Scanning electron micrographs (SEM) of fractured specimen surfaces (Figure 6(a)-(f)) revealed a good compatibility between the inorganic matrix formed of zirconium silicate nanopowder and the organic constituents, since in the SEM images are identifiable large homogeneous domains, where no voids are observed. The fracture edges are clear and sharper, feature specific for the hard materials, confirming an intimate interaction between the all components. However, in the recent research, nano-sized particles and ceramic whiskers are added to dental resins due to the fact that the high surface reactivity of nano-sized particles provides a much tighter bonding to the resin matrix than conventional-sized particles. ${ }^{38}$ In our systems, the observed aggregates/agglomerates are formed by filler crystals stacking into bundles and have dimensions under $5 \mu \mathrm{m}$. Also, it may be noticed that between the composites comprising the CAd- $1 \div$ CAd-4 oligomers (S1-S4) and the composite S5 which include the monomer CAd-M are not visible important differences, suggesting an equivalent linking of the oligomers and monomer in the resin formulations. In addition, the comparison of SEM images for the composites S1-S5 based on dicarboxylic dimethacrylate derivatives (Figure 6(a)(e)) with that containing dimethacrylate without carboxyl fragments (Figure 6(f)), sustains that the microstructure of the materials is not fundamental different, as evidenced by this technique.

For a given application is important to examine the crack opening profile in the case of our composites after they have been subjected to Vickers indentation, since fracture properties 

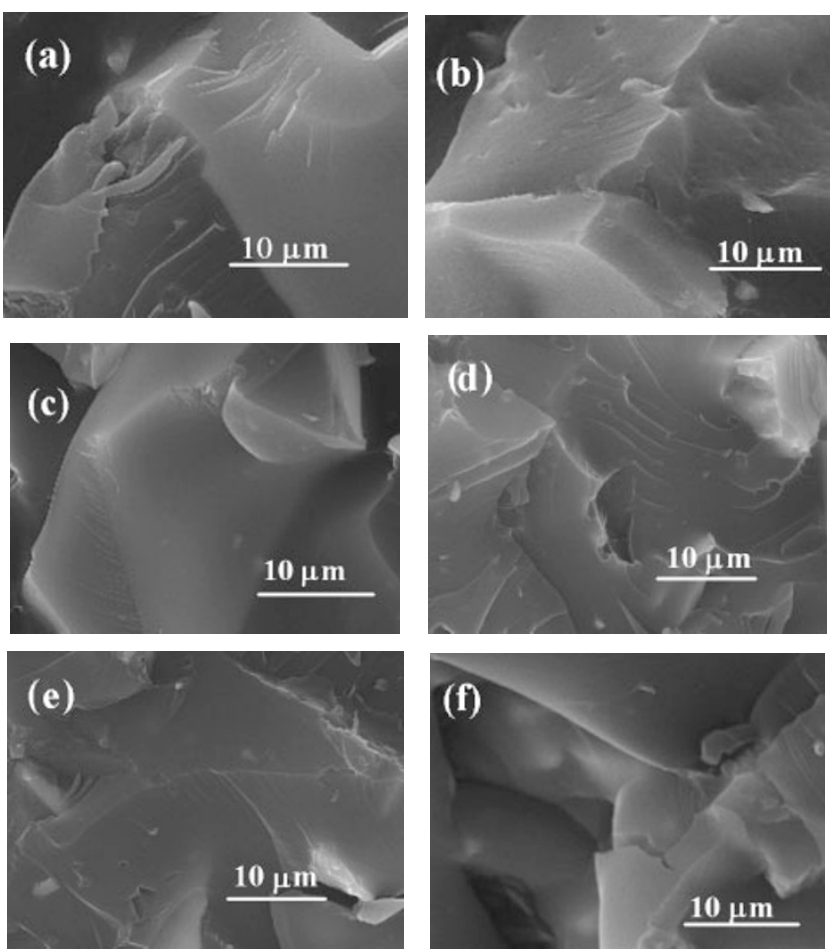

Figure 6. SEM micrographs of S1 (a), S2 (b), S3 (c), S4 (d), S5 (e) and S6 (f) resin composites in fracture.

and implicitly, fracture mechanism are key features of such materials. This fact may be related to initiation of the first microcracks formed mainly by decohesion on the particlematrix interface or by cleavage of the particles. ${ }^{39}$ Interestingly, there were published results indicating a good correlation between the hardness of dental restorative composites and the inorganic filler content, ${ }^{40}$ including the resin composition, nature of the organic/inorganic interface and the inorganic particle size distribution. ${ }^{41}$

In this study, the values of the Vickers hardness of the polymer composites S1-S6 were in the range of 30.5 to 37.7 (Table II). These results suggest that the hardness of the polymer composites varied slightly because all composites contain the same inorganic filler but different organic resin matrices. Moreover, there was a small difference (of only 3.2) in the values of the Vickers hardness of the composites incorporating the urethane dimethacrylate monomer (CAd-M, S5) or the urethane dimethacrylate oligomer with the highest PEG molecular weight (CAd-3, S3) that sustain the similarity of the resin composites under investigation.

To analyze the surface damage caused by the Vickers indentation, two methods of optical examination were employed, namely, polarizing optical microscopy (POM) and atomic force microscopy (AFM). The optical microscopy image of the resin composite S3 (Figure 7(a)) shows the characteristic Vickers indents on the surface, where four specific line are visible, but without to generate at a microscopic level the radial and lateral cracks alongside the four main lines generated of indentation. Compared to that of POM, the AFM image of the same composite (Figure 7(b)) evidenced the presence of smooth surface and a relatively uniform topographical pattern, where a linear crack seems to appear from an edge within the pyramid, resulting thus in an alteration of the surface, observable at a microscopic level. Moreover, the characteristic crack had a deep of $250 \mathrm{~nm}$, as indicated the profilometric curve attached to Figure 7(b). A similar crack was detected in the AFM image of S5 composite (unshown here) suggesting rather that the crack propagation in such composites follows most probably a relatively linear pattern. This observation is crucial for explaining the first cracks developed in dental resin composite, reason for that additional investigations will be further taken into consideration in our laboratory.

The water contact angle determinations, which are an indicative of the wetting properties of the composite resins, are presented in Table II. It can be seen that the resin composites are hydrophilic with a contact angle between 36.22 and $45.41^{\circ}$, values principally attributed to the PEG sequences. Although, the presence of carboxyl groups into the S3 formulation determines a decreasing of contact angle with $4.5^{\circ}$ as compared to the homologue S6, where there are no carboxyl moieties, it is evidently the contribution of such units on the total
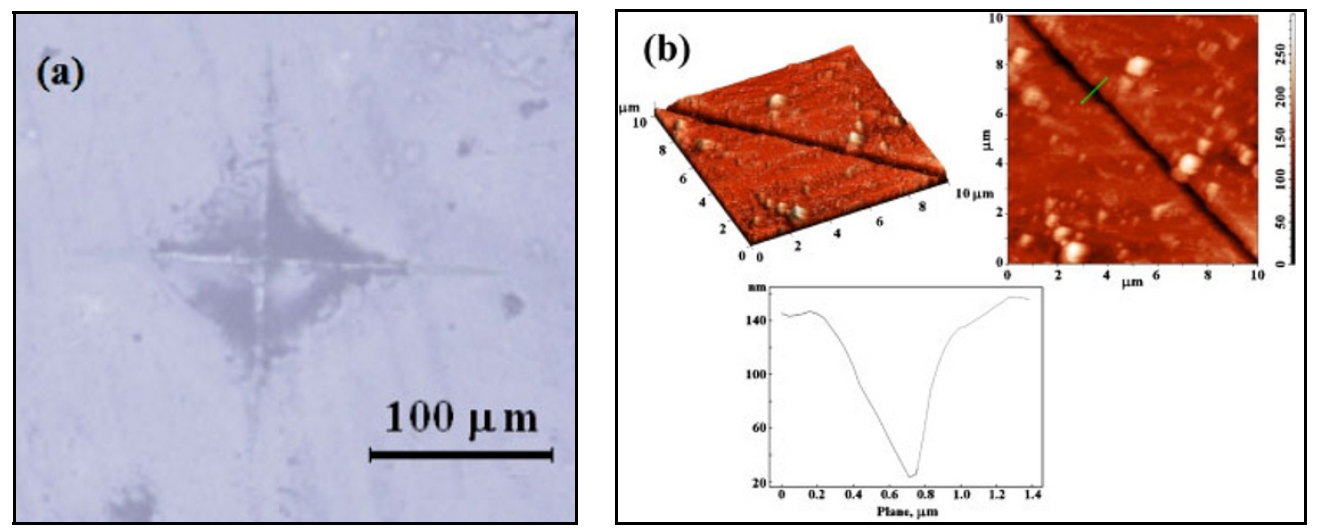

Figure 7. Optical microscopic image of the Vickers indentations in resin composite $\mathrm{S} 3(\mathrm{a})$ and the $2 \mathrm{D}$ and $3 \mathrm{D}$ AFM micrographs of the crack in the S3 composite as well as the clear changes in the depth profile. 


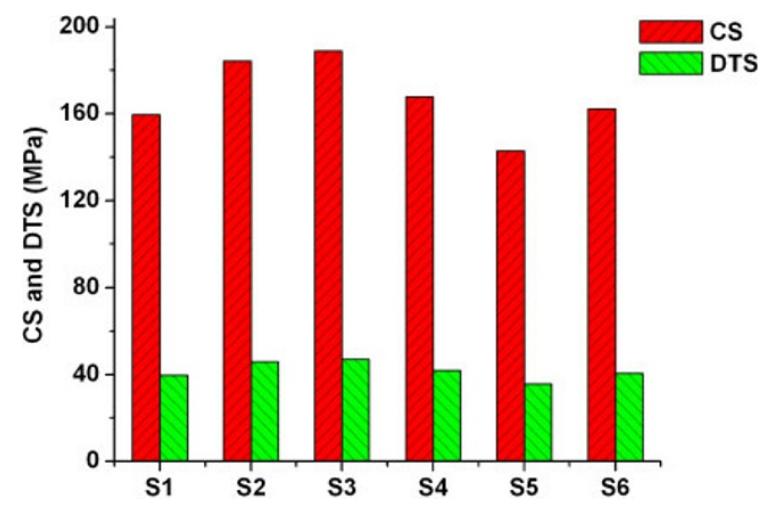

Figure 8. Compressive (CS) and diametral tensile strength (DTS) for the experimental resins composites.

hydrophilicity of the resulting materials. From this perspective, the above elements would be helpful for the design of materials that require a more hydrophilic structure and proper water solubility, such as adhesive bonding to dental and other hydrophilic surfaces or in obturation systems, but first results will be presented in the near future.

\section{Mechanical Properties}

Diametral tensile strength (DTS) and compressive strength (CS) are commonly used in the evaluation of dental material formulations. ${ }^{42,43}$ Consequently, the composites containing the dimethacrylate urethane carboxylic oligomers or monomer mixed with BisGMA and TEGDMA together with 70 wt. \% inorganic filler (zirconium silicate nanopowder) were tested to evaluate their mechanical parameters. The results obtained for the composites S1-S6 concerning the diametral tensile and compressive strengths are included in Figure 8. In fact, the values found in the case of all composites containing $15 \mathrm{wt} \%$ dicarboxylic urethane dimethacrylate of oligomeric type (DTS: 35.7-47.2 MPa; CS: $159.5-188.9 \mathrm{MPa}$ ) are rather comparable to those reported for some glass ionomer cements. ${ }^{44}$ Also, it may be noted that the lower values for the DTS $(35.7 \mathrm{MPa})$ and CS $(142.8 \mathrm{MPa})$ are recorded in the case of CAd-M monomer, when is supposed that the short molecular chains induce an inferior cohesion between the organic and inorganic matrixes. Therefore, the presence of carboxyl groups into the formulations determines an increasing of the mechanical parameters as compared to the noncarboxylic composite (S6), behaviour attributed to a better interaction between all components.

\section{CONCLUSIONS}

New carboxylic acid urethane dimethacrylates containing polyethylene oxide of variable length were synthesized to be photo(co)polymerized with other monomers, demonstrating the potential of this approach for production of dental composite resins. Preliminary results show that the urethane dimethacrylates with diacid functionality manifests a high conversion degree (around $60 \%$ after $35 \mathrm{~s}$ of UV-vis irradiation), good water behaviour and polymerization shrinkage, whereas the mechanical properties of the formed composites that contain small quantities of dimethacrylate oligomers situate them closer to the glass ionomer resins.

Acknowledgment. The authors thank to the Ministry of Research and Education and the board of MATNANTECH program for the financial support of this work through a project from the National Research Program (Nr. 1306/2005).

Received: May 28, 2009

Accepted: July 24, 2009

Published: September 4, 2009

\section{REFERENCES}

1. N. Moszner and U. Salz, Prog. Polym. Sci., 26, 535 (2001).

2. K. L. Van Landuyt, J. Snauwaert, J. De Munck, M. Peumans, Y. Yoshida, A. Poitevin, E. Coutinho, K. Suzuki, P. Lambrechts, and B. Van Meerbeek, Biomaterials, 28, 3757 (2007).

3. S. H. Dickens and B. H. Cho, Dent. Mater., 21, 354 (2005).

4. C. Santos, R. L. Clarke, M. Braden, F. Guitian, and K. W. M. Davy, Biomaterials, 23, 1897 (2002).

5. I. D. Sideridou, M. M. Karabela, and D. N. Bikiaris, Dent. Mater., 23, 1142 (2007).

6. M. Toledano, R. Osorio, E. Osorio, V. Fuentes, C. Prati, and F. Garcia-Godoy, J. Dentistry, 31, 43 (2003).

7. D. Skrtic and J. M. Antonucci, Biomaterials, 24, 2881 (2003).

8. M. Y. Jeon, S. H. Yoo, J. H. Kim, C. K. Kim, and B. H. Cho, Biomacromolecules, 8, 2571 (2007).

9. N. Moszner, U. K. Fischer, J. Angermann, and V. Rheinberger, Dent. Mater., 24, 694 (2008).

10. B. K. Norling and N. Satsangi, U. S. Patent 7094358 B2 (2006).

11. Q. Wan, D. Rumpf, S. R. Schricker, A. Mariotti, and B. M. Culbertson, Biomacromolecules, 2, 217 (2001).

12. N. Moszner, A. Gianasmidis, S. Klapdohr, U. K. Fischer, and V. Rheinberger, Dent. Mater., 24, 851 (2008).

13. K. S. Anseth, M. D. Goodner, M. A. Reil, A. R. Kannurpatti, S. M. Newman, and C. N. Bowen, J. Dent. Res., 75, 1607 (1996).

14. K. Zhang, C. G. Simon, N. R. Washburn, J. M. Antonucci, and S. Lin-Gibson, Biomacromolecules, 6, 1615 (2005).

15. F. Lopez-Suevos and S. H. Dickens, Dent. Mater., 24, 778 (2008).

16. M. T. O'Connor, Jr., Polym. Prepr. (Am. Chem. Soc., Div. Polym. Chem.), 44, 219 (2003).

17. N. Moszner, J. Pavlinec, and J. Angermann, Macromol. Chem. Phys., 208, 529 (2007).

18. N. Moszner, J. Pavlinec, I. Lamparth, F. Zeuner, and J. Angermann, Macromol. Rapid Commun., 27, 1115 (2006).

19. C. A. Khatri, J. W. Stansbury, C. R. Schultheisz, and J. M. Antonucci, Dent. Mater., 19, 584 (2003).

20. A. Ellakwa, N. Cho, and I. B. Lee, Dent. Mater., 23, 1229 (2007).

21. D. Skrtic, J. M. Antonucci, and D.-W. Liu, Acta Biomaterialia, 2, 85 (2006).

22. C.-Y. Chen, C.-K. Huang, S.-P. Lin, J.-L. Han, K.-H. Hsieh, and C.-P. Lin, Comp. Sci. Technol., 68, 2811 (2008).

23. E. C. Buruiana, T. Buruiana, V. Melinte, M. Zamfir, A. Colceriu, and M. Moldovan, J. Polym. Sci., Part A: Polym. Chem., 45, 1956 (2007).

24. T. Buruiana, E. C. Buruiana, V. Melinte, V. Pohoata, C. Prejmerean, and M. Moldovan, J. Optoelectron. Adv. Mater., 10, 969 (2008).

25. T. Buruiana, E. C. Buruiana, V. Melinte, A. Colceriu, and M. Moldovan, Polym. Eng. Sci., 49, 1127 (2009).

26. H. Kilambi, J. W. Stansbury, and C. N. Bowman, Macromolecules, 40, 47 (2007).

27. P. Krol, Prog. Mater. Sci., 52, 915 (2007).

28. C.-M. Chung, J.-G. Kim, and J.-H. Choi, J. Appl. Polym. Sci., 77, 1802 (2000). 
29. B. M. Culbertson, Prog. Polym. Sci., 26, 577 (2001).

30. W. F. Jager, D. Kudasheva, and D. C. Neckers, Macromolecules, 29, 7351 (1996).

31. S. G. Pereira, G. N. Nunes, and S. Kalachandra, Biomaterials, 23, 3799 (2002).

32. A. Prakki, P. Tallury, R. F. L. Mondelli, and S. Kalachandra, Dent. Mater., 23, 1199 (2007).

33. Z. Tarle, A. Meniga, M. Ristic, J. Sutalo, and G. Pichler, Croat. Chem. Acta, 71, 777 (1998).

34. J. Malacarne, R. M. Carvalho, M. F. de Goes, N. Svizero, D. H. Pashley, F. R. Tay, C. K. Yiu, and M. R. de Oliveira Carrilho, Dent. Mater., 22, 973 (2006).

35. M. S. Soh and A. U. J. Yap, J. Dentistry, 32, 321 (2004).

36. I. D. Sideridou, M. M. Karabela, and E. C. Vouvoudi, Dent. Mater., 24, 1131 (2008).

37. C. Domingo, R. W. Arcis, E. Osorio, R. Osorio, M. A. Fanovich,
R. Rodriguez-Clemente, and M. Toledano, Dent. Mater., 19, 478 (2003).

38. M. Tian, Y. Gao, Y. Liu, Y. Liao, N. E. Hedin, and H. Fong, Dent. Mater., 24, 235 (2008).

39. E. Apel, J. Deubener, A. Bernard, M. Höland, R. Müller, H. Kappert, V. Rheinberger, and W. Höland, J. Mech. Behav. Biomed. Mater., 1, 313 (2008).

40. D. B. Boyer, Y. Chaklley, and K. C. Chan, J. Biomed. Mater. Res., 16, 775 (1982).

41. J. Manhart, K. H. Kunzelmann, H. Y. Chen, and R. Hickel, J. Biomed. Mater. Res., 53, 353 (2000).

42. L. Rojo, B. Vazquez, J. San Roman, and S. Deb, Dent. Mater., 24, 1709 (2008).

43. J. W. Kim, L. U. Kim, C. K. Kim, B. H. Cho, and O. Y. Kim, Biomacromolecules, 7, 154 (2006).

44. J. W. Nicholson, Dent. Mater., 23, 615 (2007). 